\title{
Effects of environmental complexity on emotionality and avoidance performance of Tryon S1 and S3 strains
}

BARBARA J. POWELL, GALESBURG STATE RESEARCH HOSPITAL MADGE LEACH, KNOX COLLEGE

Females from the Tryon $S 1$ and $S 3$ strains were subjected at weaning to 50 days in an enriched, neutral or impoverished environment and subsequently tested for open field emotionality and avoidance performance. There was no significant effect of environment on either emotionality or avoidance performance; however, strain differences were found for both measures. The $S 3$ s were less emotional and had better avoidance performance than the S1s.

Genotypic variations in such characteristics as adult emotionality and maze learning ability have been reliably produced by a process of selective breeding. However, such strain differences can be altered through experimental manipulations of the early environment. Thus infantile stimulation (e.g., handling) of the rat and manipulation of early environmental complexity have been associated with adult emotional reactivity and learning ability, respectively. For example, Cooper \& Zubek (1958) found that differences in maze performance of the McGill bright and dull strains could be eliminated through selective environmental rearing. Subsequently, Levine \& Broadhurst (1963) have reported that infantile stimulation significantly affected emotionality and avoidance learning differences in the Maudsley strains, with the greatest effect being on the reactive strain.

In a previous study (Powell, Martin, \& Kamano, 1967) it was found that descendants of the Tryon S1 and S3 strains reared under uniform conditions differed not only in terms of avoidance performance but also in open field emotionality, with the less emotional S3s performing better than the more emotional S1s during avoidance acquisition. The present study was undertaken to determine what effect, if any, rearing conditions involving enriched, neutral, and impoverished environments would have on the subsequent emotionality and avoidance performance of female rats from the Tryon S1 and S3 strains.

Subjects

The Ss were $27 \mathrm{~S} 1$ and $18 \mathrm{~S} 3$ female weanling rats (descendants of the Tryon strain) obtained from the colony maintained at the Psychology Laboratory, Galesburg State Research Hospital.

Apparatus

All Ss were housed in $22 \times 14 \times 13$ in. wire mesh cages which were identical except as noted below. Separate housing was provided for each strain. The six cages were housed on a single rack, with the enriched environments on the top tier, and the neutral and impoverished environments on the middle and lower tlers, respectively. The neutral environment involved standard laboratory rearing conditions. The impoverished environment was identical with the neutral, except the cage was completely covered with heavy burlap cloth, thus creating a relatively bland visual, tactual, and kinesthetic environment. The erriched environment was similar to that described by Krech, Rosenzweig, \& Bennett (1960). Specifically, it contained: a red ball, butlding block, and spinning top, all freely suspended from the top of the cage by a chain, to within 2 in. of the floor; a 5 in. high three rung metal ladder; and a modified activity wheel attached to the side of the cage, which $S$ could enter and leave as desired. In addition, a wooden platform was affixed to the rear of the cage and $S$ was required to get on the platform in order to obtain food and water. Food and water were available, ad lib, in all environments.

The open field apparatus is described elsewhere (Martin, Powell, \& Kamano, 1966). The avoidance apparatus was a modified Miller-Mowrer box, which together with the US and CS are described in detail elsewhere (Powell, Martin, \& Kamano, 1965).

Procedure

At weaning (21 to 25 days of age) Ss were ear punched for identification and assigned by the split litter technique to one of the three environments where they remained undisturbed and unhandled for 50 days. At the end of this time, Ss were tested for open field emotionality which was assessed by the number of ambulations and defecation-urinations (D-Us) occurring during a $3 \mathrm{~min}$ session (for four consecutive days) in the open field. Avoidance conditioning, which followed immediately, involved 80 massed trials in the jump box apparatus. Each trial consisted of light onset (CS) followed 5 sec later by shock (US intensity $=250 \mu \mathrm{A}$ ) which continued until $\mathrm{S}$ jumped the hurdle into the adjoining compartment, or, if $S$ failed to escape, for a maximum of $20 \mathrm{sec}$. The intertrial interval ranged from 20 to $40 \mathrm{sec}$, and crossing the hurdle during the 5 sec CS-US interval constituted a conditioned avoidance response (CAR).

\section{Results and Discussion}

The mean open field ambulation and D-U scores from the four day period of open field testing for Ss from each environmental condition are presented in Table 1 along with mean CAR scores. All scores were 
Table 1 Mean ambulation, D-U, and CAR scores by Ss from each environment

\begin{tabular}{lrcccccccc}
\hline Group & \multicolumn{3}{c}{ Enriched } & \multicolumn{3}{c}{ Neutral } & \multicolumn{3}{c}{ Impoverished } \\
& AMB. & D-U & CARs & AMB. & D-U & CARs & AMB. & D-U & CARs \\
\hline S1 & 14 & 5 & 23 & 45 & 5 & 27 & 28 & 6 & 25 \\
$(\mathrm{~N}=27)$ & & & & & & & & & \\
$\mathrm{S} 3$ & 102 & 0 & 32 & 115 & 4 & 47 & 114 & 0 & 46 \\
$(\mathrm{~N}=18)$ & & & & & & & & & \\
\hline
\end{tabular}

subjected to separate analyses of variance with unequal $\mathrm{N}$ corrected for by the unweighted mean procedure (Winer, 1962, p. 242).

Both measures of open field emotionality yielded consistent strain differences, with S3s (dulls) having more ambulations and fewer defecations than S1s (brights) $(F=57.82, p<.01$ and $F=8.37, p<.01$, respectively); however, there was no significant effect of environment ( $F=1.60$ and $F=1.04$, respectively). The analysis of CAR scores yielded significant effects of strain, with the less emotional S3s emitting more CARs than the more emotional S1s $(F=13.62, p<.01)$. Again, the effects of environment were not significant ( $F=1.63)$.

The finding that S1s were more emotional than S3s was consistent with results from a previous study (Powell, Martin, \& Kamano, 1967), as was the general finding that less emotional rats tend to have better avoidance performance than more emotional rats (Martin, Powell, \& Kamano, 1966; Powell, 1967). Despite the fact that the rearing environments appeared to have no differential effect on either emotionality or avoidance performance, the group means of open field ambulation for SIs were more dissimilar than comparable group means of the S3s. Although limited, the implication of this result is similar to Broadhurst \& Levine's (1962) findings in that the more emotional Ss tended to be more affected by environmental conditions than the less emotional Ss.

In summary, the results of this study suggest that the particular environmental experiences used were not effective in altering either emotionality or avoidance performance differences; however, this does not mean that differences in emotionality are unalterable, but suggests that compared to the more reliable effect of preweaning handling, postweaning experiences are relatively ineffective.

\section{References}

COOPER, R. M., \& ZUBEK, J. P. Effects of enriched and restricted early environment on the learning ability of bright and dull rats. Canad. $J$. Psychol, 1958, 12, 159-164.

KRECH, D., ROSENZWEIG, M. R., \& BENNETT, E. L. Effects of environmental complexity and training on brain chemistry. J. comp. physiol. Psychol, 1960, 53, 509-519.

LEVINE, E., \& BROADHURST, P. L. Genetic and ontogenetic determinants of adult behavior in the rat. J. comp. physiol. Psychol, 1963, $56,423-428$

MARTIN, L. K., POWELL, BARBARA J., \& KAMANO, D. K. Effect of amobarbital on avoidance performance of rats differing in emotionality. Proc. 74th Amer. Psychol Conv., New York, 1966, 125-126.

POWELL, BARBARA J., MARTIN, L. K., \& KAMANO, D. K. Effects of amobarbital sodium and meprobamate on acquisition of conditioned avoidance. Psychol Rep., 1965, 17, 691-694.

POWELL, BARBARA J., MARTIN, L. K., \& KAMANO, D. K. Relationship between emotionality, drug effects and avoidance responses in Tryon S1 and S3 strains. Canad. J. Psychol, in press.

POWELL, BARBARA J. Prediction of drug action: elimination of error through emotionality. Proc. 75th Amer. Psychol. Conv., Washington, D. C., 1967, in press.

WINER, B. J. Statistical principles in experimental design. New York: McGraw-Hill, 1962 